\title{
Polymerization of Substituted Acetylenes by the Grubbs-Hoveyda Ru Carbene Complex
}

\author{
Toru Katsumata, ${ }^{1}$ Masashi ShiOTSUKI, ${ }^{1}$ Shigeki KUROKI, ${ }^{2}$ \\ Isao ANDO, ${ }^{2}$ and Toshio MASUDA ${ }^{2, \dagger}$ \\ ${ }^{1}$ Department of Polymer Chemistry, Graduate School of Engineering, Kyoto University, \\ Kyoto University Katsura, Sakyo-ku, Kyoto 615-8510, Japan \\ ${ }^{2}$ Department of Chemistry and Materials Science, Tokyo Institute of Technology, \\ International Research Center of Macromolecular Science, 2-12-1 Ookayama, Meguro-ku, Tokyo 152-8552, Japan
}

(Received April 1, 2005; Accepted May 18, 2005; Published August 15, 2005)

\begin{abstract}
Polymerization of various mono- and disubstituted acetylenes was investigated by using GrubbsHoveyda catalyst (1). Hexyl propiolate (2) and 1-phenyl-2-( $p$-trimethylsilyl)phenylacetylene (3) polymerized in moderate yields. Bulk polymerization of 2 at $[\mathrm{M}]_{0} /[\mathrm{Ru}]=100$ and $80^{\circ} \mathrm{C}$ for $24 \mathrm{~h}$ afforded poly $(2)$ having $M_{\mathrm{n}}=25,500$ and $M_{\mathrm{w}} / M_{\mathrm{n}}=2.63$. This polymer possessed relatively high cis content (75\%) according to NMR. Monomer 3 polymerized in bulk to yield poly $(3)$ with $M_{\mathrm{n}}=60,700, M_{\mathrm{w}} / M_{\mathrm{n}}=2.22$ under conditions of $80^{\circ} \mathrm{C}, 24 \mathrm{~h},[\mathrm{M}]_{0} /[\mathrm{Ru}]=25$. The Ru-based poly $(3)$ displayed a narrower conjugation than those obtained with other catalysts. The ${ }^{13} \mathrm{C}$ NMR spectra of this polymer in solid and solution states showed quite different signal patterns from those with conventional catalysts, suggesting a different geometric structure of main chain. [DOI 10.1295/polymj.37.608]
\end{abstract}

KEY WORDS Substituted Polyacetylene / Ru Carbene Complex /

Substituted polyacetylenes have been gathering much attention due to their potential applications to material-separation membranes, and optoelectronic and related fields. ${ }^{1}$ These polymers have been obtained by polymerization of corresponding acetylenic monomers in the presence of transition metal catalysts. Catalysts including group 5 and 6 transition metal and $\mathrm{Rh}$ have traditionally been employed to induce their polymerization. Among them, halides of early transition metals such as $\mathrm{TaCl}_{5}, \mathrm{NbCl}_{5}, \mathrm{MoCl}_{5}$, and $\mathrm{WCl}_{6}$ in conjunction with organometallic cocatalysts polymerize various mono- and disubstituted acetylenes to give high molecular weight polymers in good yield. Some well-defined Ta, Mo, and W carbenes, so-called Schrock carbenes, induce living polymerization of substituted acetylenes. ${ }^{2-5}$ This implies that the group 5 and 6 transition metal-catalyzed polymerization proceeds by the metathesis mechanism. One of the drawbacks of the early transition metal is that they are readily deactivated by polar groups in the monomer and polymerization solvents because of their high oxophilicity.

Another type of catalysts frequently used for the polymerization of substituted acetylenes are rhodium (Rh) catalysts. Rh catalysts can polymerize only monosubstituted acetylenes such as phenylacetylene and its ring-substituted derivatives, ${ }^{6-11} \mathrm{~N}$-propargylamides, ${ }^{12-17}$ and propiolic esters. ${ }^{19-23}$ The Rh-catalyzed polymerization proceeds by the insertion mechanism, and features excellent tolerance to polar sub- situents in the monomer ${ }^{24,25}$ and protic solvents. ${ }^{26}$ The Rh-based polymers generally possess high cis stereoregularity, which is indispensable for the formation of helical structures of poly( $N$-propargylamide)s. ${ }^{12-17}$

A huge number of studies on the synthesis and catalysis of ruthenium $(\mathrm{Ru})$ carbene complexes have been reported in these several years. $\mathrm{Ru}$ carbene complexes represented by Grubbs' first- and secondgeneration catalysts exhibit high activity in olefin metathesis reactions such as ring-opening metathesis polymerization (ROMP), ring-closing metathesis (RCM), cross metathesis (CM). ${ }^{27}$ Compared to early transition metal-based metathesis catalysts, Ru carbene complexes display tolerance against protic functional groups in these metathesis reactions as well as considerable stability to oxygen and moisture. It should also be noted that many Ru complexes have well-defined carbene structures, which enables to directly generate carbene-type active species without adding cocatalysts. The Grubbs' second-generation complex reportedly reacts with diphenylacetylene stoichiometrically to afford $\eta^{3}$-vinylcarbene complex, which is regarded as an intermediate of the polymerization of acetylenes. ${ }^{28} \mathrm{Ru}$-catalyzed polymerizations of acetylene ${ }^{29}$ and diyne compounds ${ }^{30,31}$ have recently been reported. Though an Ru carbene complex bearing 3-bromopyridine polymerizes not only acetylene but also its several derivatives, the substituted polyacetylenes formed have not been mentioned in detail. ${ }^{29}$ Buchmeiser and coworkers developed living

${ }^{\dagger}$ To whom correspondence should be addressed (Tel: +81-75-383-2589, Fax: +81-75-383-2590, E-mail: masuda@adv.polym.kyoto-u.ac.jp). 


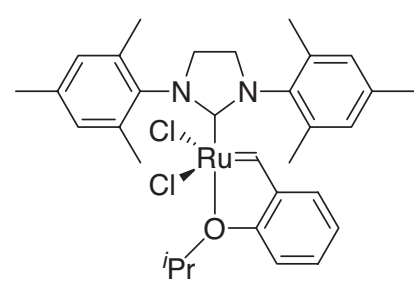

Grubbs-Hoveyda catalyst 1

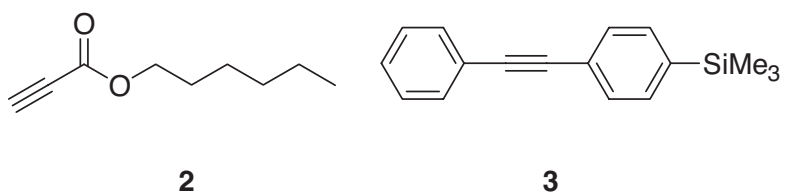

Chart 1. polymerization systems by using diethyl dipropargylmalonate as monomer and mainly $\mathrm{Ru}$ carbenes containing trifluoroacetate ligands as catalysts. ${ }^{30,31}$ These facts prompted us to examine the polymerization of various mono- and disubstituted acetylenes by an active $\mathrm{Ru}$ carbene catalyst.

This paper reports on the polymerization of the substituted acetylenes using the Grubbs-Hoveyda Ru carbene $(\mathbf{1})^{32-34}$ which is one of the most active $\mathrm{Ru}$ catalysts in metathesis reactions (Chart 1). Hexyl propiolate (2), 1-phenyl-2-( $p$-trimethylsilyl)phenylacetylene (3), phenylacetylene, 1-octyne, etc. were used as monomers. Among these monomers, $\mathbf{2}$ and $\mathbf{3}$ afforded polymers in moderate yields in bulk polymerization. The geometric structure and properties of poly(2) and poly(3) were elucidated by NMR and other analytical methods.

\section{EXPERIMENTAL}

\section{General}

The molecular weights of polymers were estimated by gel permeation chromatography (THF as eluent, Showa Denko Shodex KF-805L ×3, polystyrene calibration). IR spectra were recorded on a Shimadzu FTIR-8100 spectrophotometer. ${ }^{1} \mathrm{H}(400 \mathrm{MHz})$ and ${ }^{13} \mathrm{C}$ NMR (100 MHz) spectra were measured in $\mathrm{CDCl}_{3}$ solution on a JEOL EX-400 spectrometer. Chemical shifts $(\delta)$ for ${ }^{1} \mathrm{H}$ and ${ }^{13} \mathrm{C}$ are referenced to internal solvent resonances and shown relative to tetramethylsilane. Thermogravimetric analyses (TGA) were conducted in air with a Perkin-Elmer TGA7 thermal analyzer. Ultraviolet-visible (UV-vis) and emission spectra were measured on Jasco V-550 and FP-750 spectrophotometers, respectively. Monomer conversions were determined by GC (Shimadzu GC-8A; Silicone SE30 (5\% on Chromosorb W(AW-DMCS), 80-100 mesh); injection and column temperatures were 250 and $230{ }^{\circ} \mathrm{C}$, respectively) using cyclododecane as an internal standard.

\section{Solid-State ${ }^{13} C$ NMR Measurements $(C P / M A S$ and $C P+D D P h)$ \\ The ${ }^{13} \mathrm{C}$ NMR spectra were recorded on a Bruker}

Avance DSX300 NMR $(75.6 \mathrm{MHz})$ spectrometer at room temperature. A conventional $4 \mathrm{~mm}$ wide-bore $\mathrm{CP} / \mathrm{MAS}$ probehead was used; the contact time was $2 \mathrm{~ms}$ and the $\pi / 2$ pulse width was $3.2 \mu$ s for ${ }^{1} \mathrm{H}$. The ${ }^{13} \mathrm{C}$ chemical shifts were calibrated by using adamantane $(\delta=29.5 \mathrm{ppm})$ as an external standard relative to tetramethylsilane $(\delta=0 \mathrm{ppm})$.

\section{Materials}

Grubbs-Hoveyda catalyst 1 was offered by Materia (USA). $\mathrm{TaCl}_{5}$ (Strem Chemicals), $\mathrm{WCl}_{6}$ (Aldrich), $\mathrm{MoCl}_{5}$ (Aldrich), $\mathrm{MoOCl}_{4}$ (Aldrich), and $\mathrm{WOCl}_{4}$ (Aldrich) as main catalyst components and $\mathrm{Ph}_{4} \mathrm{Sn}$ (Wako Pure Chemical) as a cocatalyst were used without further purification. $n$ - $\mathrm{Bu}_{4} \mathrm{Sn}$ (Wako Pure Chemical) as a cocatalyst, and 1-octyne (TCI) and phenylacetylene (Aldrich) as monomers were purified by distillation. Monomers $2,{ }^{21} \mathbf{3},{ }^{35} \mathrm{~N}$-propargylhexanamide, ${ }^{18}$ and $[(\mathrm{nbd}) \mathrm{RhCl}]_{2}{ }^{36}$ were prepared according to the literature methods. Toluene, THF, 1,2-dichloroethane, and acetonitrile as solvents for polymerization were purified by distillation, and DMSO and ethyl acetate were used as received (Wako Pure Chemical).

\section{Bulk Polymerization}

Polymerizations were performed in a Schlenk tube equipped with a three-way stopcock under argon. Unless otherwise specified, the reactions were carried out for $24 \mathrm{~h}$. The following procedure is exemplary: Monomer 2a $(0.15 \mathrm{~g}, 1.0 \mathrm{mmol})$ was added to a Schlenk tube that had been charged with catalyst $\mathbf{1}$ $(6.3 \mathrm{mg}, 10 \mu \mathrm{mol})$ beforehand. Polymerization was carried out at $80^{\circ} \mathrm{C}$ for $24 \mathrm{~h}$. The formed polymer was dissolved in toluene $(2.0 \mathrm{~mL})$ and isolated by precipitation into a large excess of methanol, filtered, and dried under vacuum to constant weight. Its yield was determined by gravimetry.

\section{Solution Polymerization}

Unless otherwise specified, polymerizations were carried out in an argon atmosphere for $24 \mathrm{~h}$ under the following conditions: $[\mathrm{M}]_{0}=0.50 \mathrm{M},[\mathrm{Ru}]=10$ $\mathrm{mM}$. A detailed procedure of polymerization is as follows: A monomer solution was prepared in a Schlenk 
Table I. Bulk polymerization of $\mathbf{2}$ by catalyst $\mathbf{1}$

\begin{tabular}{ccccccc}
\hline & & & & \multicolumn{4}{c}{ Polymer $^{\mathrm{a}}$} \\
\cline { 5 - 7 } Run & $\begin{array}{c}\text { Temperature } \\
\left({ }^{\circ} \mathrm{C}\right)\end{array}$ & {$[\mathrm{M}]_{0} /[\mathrm{Ru}]$} & $\begin{array}{c}\text { Time } \\
(\mathrm{h})\end{array}$ & $\begin{array}{c}\text { Yield } \\
(\%)\end{array}$ & $M_{\mathrm{n}}{ }^{\mathrm{b}}$ & $M_{\mathrm{w}} / M_{\mathrm{n}}{ }^{\mathrm{b}}$ \\
\hline 1 & 60 & 100 & 24 & 12 & 43,400 & 2.48 \\
2 & 80 & 100 & 24 & 24 & 25,500 & 2.63 \\
3 & 120 & 100 & 24 & 0 & $(1900)^{\mathrm{c}}$ & $(1.11)^{\mathrm{c}}$ \\
4 & 80 & 25 & 24 & 0 & $(1500)^{\mathrm{c}}$ & $(1.05)^{\mathrm{c}}$ \\
5 & 80 & 50 & 24 & 5 & 20,900 & 1.86 \\
6 & 80 & 200 & 24 & 23 & 21,500 & 2.65 \\
7 & 80 & 200 & 168 & 28 & 23,800 & 2.35 \\
\hline
\end{tabular}

${ }^{\mathrm{a}}$ Methanol-insoluble part. ${ }^{\mathrm{b}}$ Measured by GPC. ${ }^{\mathrm{c}}$ Methanolsoluble part.

tube with a three-way stopcock by mixing monomer 2a $(0.15 \mathrm{~g}, 1.0 \mathrm{mmol})$ and toluene $(1.0 \mathrm{~mL})$, and another Schlenk tube was charged with catalyst $\mathbf{1}$ $(13 \mathrm{mg}, 20 \mu \mathrm{mol})$ and toluene $(1.0 \mathrm{~mL})$. Polymerization was initiated by adding the monomer solution to the catalyst solution, and continued at $60^{\circ} \mathrm{C}$ for $24 \mathrm{~h}$. Then the reaction was quenched by adding a small amount of methanol. The formed polymer was isolated by precipitation into a large excess of methanol, filtered, and dried under vacuum to constant weight, whose yield was determined by gravimetry.

\section{RESULTS AND DISCUSSION}

\section{Polymerization of Monomer 2}

Bulk polymerization of monomer $\mathbf{2}$ was at first studied in detail (Table I). The effect of polymerization temperature was examined keeping at $[\mathrm{M}]_{0} /$ [cat $]=100$ and time $=24 \mathrm{~h}$. At $60^{\circ} \mathrm{C}$, polymer was obtained in $12 \%$ yield, whose $M_{\mathrm{n}}$ was 43,400 (run 1). With increasing temperature, the polymer yield tended to increase, while the $M_{\mathrm{n}}$ of polymer decreased. Thus, the polymer yield increased to $24 \%$ at $80^{\circ} \mathrm{C}$, while only methanol-soluble oligomers formed at $120^{\circ} \mathrm{C}$ (runs 2, 3). Next, the $[\mathrm{M}]_{0} /$ [cat] ratio was varied while keeping the polymerization temperature at $80^{\circ} \mathrm{C}$. Even though $[\mathrm{M}]_{0} /[\mathrm{cat}]$ ratio was increased to 200 , no significant difference was observed in polymer yield and molecular weight (run 6). On the other hand, decreases in the $[\mathrm{M}]_{0} /$ [cat] ratio resulted in lower yields and $M_{\mathrm{n}}$ 's (runs $4,5)$. This suggests that methanol-soluble oligomers are mainly formed at high catalyst concentrations. The polymerization seems to level off after a certain period of time, because the polymer yield did not obviously increase even after $7 \mathrm{~d}$ (run 7).

Solution polymerization catalyzed by $\mathbf{1}$ proceeded with monomer 2. Among toluene, THF, 1,2-dichloroethane, acetonitrile, ethyl acetate, and DMSO as polymerization solvents, toluene usually achieved the
Table II. Solution polymerization of $\mathbf{2}$ by catalyst $\mathbf{1}^{\mathrm{a}}$

\begin{tabular}{ccccc}
\hline & & \multicolumn{3}{c}{ Polymer $^{\mathrm{b}}$} \\
\cline { 3 - 5 } Run & $\begin{array}{c}\text { Temperature } \\
\left({ }^{\circ} \mathrm{C}\right)\end{array}$ & $\begin{array}{c}\text { Yield } \\
(\%)\end{array}$ & $M_{\mathrm{n}}{ }^{\mathrm{c}}$ & $M_{\mathrm{w}} / M_{\mathrm{n}}{ }^{\mathrm{c}}$ \\
\hline 1 & 50 & 0 & - & - \\
2 & 55 & Trace & - & - \\
3 & 60 & 6 & $1,400,000(14 \%)^{\mathrm{d}}$ & 1.15 \\
4 & 65 & 4 & 41,000 & 3.47 \\
5 & 70 & 13 & 37,500 & 2.61 \\
6 & 80 & 18 & 19,900 & 2.60 \\
7 & 90 & 0 & - & - \\
\hline
\end{tabular}

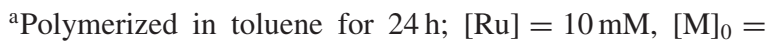
$0.50 \mathrm{M}$. ${ }^{\mathrm{b}}$ Methanol-insoluble part. ${ }^{\mathrm{c}}$ Measured by GPC. ${ }^{\mathrm{d}} \mathrm{Peak}$ area ratio in GPC.

highest polymer yields. Detailed results using toluene as solvents are shown in Table II. Whereas only trace or no polymer was obtained at $55{ }^{\circ} \mathrm{C}$ and below in toluene (runs 1,2 ), polymerization proceed at $60^{\circ} \mathrm{C}$ to give in $6 \%$ yield a polymer having bimodal $\operatorname{MWD}\left(M_{\mathrm{n}}=1,400,000\right.$ and 32,900, run 3). The polymer yield was improved by raising the polymerization temperature, while an adverse effect was observed for molecular weight. With increasing temperature, the bimodal peak in GPC chart changed into a single peak bearing a shoulder with wide polydispersity at $65^{\circ} \mathrm{C}$ and a unimodal peak at $70^{\circ} \mathrm{C}$ (runs 4,5 ). The polymer yield increased to $18 \%$ at $80^{\circ} \mathrm{C}$ (run 6) as in bulk polymerization, while no methanol-insoluble polymer was obtained at $90^{\circ} \mathrm{C}$ (run 7).

\section{Structure and Properties of Poly(2)}

It has been reported that monomer 2 can be polymerized by Rh, Mo, W catalyst systems and that the formed polymers possess different geometric structures depending on the catalysts used. ${ }^{23}$ More specifically, the poly(propiolic ester)s obtained with $\mathrm{Rh}$ catalysts have high cis contents, while trans-rich polymers are obtained with Mo and $\mathrm{W}$ catalysts. Actually poly(2) samples were prepared in this study by using $[(\mathrm{nbd}) \mathrm{RhCl}]_{2}, \mathrm{MoOCl}_{4} / n-\mathrm{Bu}_{4} \mathrm{Sn}$, and $\mathrm{WOCl}_{4} /$ $n$-Bu $\mathrm{Bu}_{4} \mathrm{Sn}$ to compare the geometric structure with that obtained with $\mathrm{Ru}$ catalyst 1 (Table III), and the ${ }^{1} \mathrm{H}$ NMR spectra of the poly(2)s were depected in Figure 1. In general, it is known that the polymerization of monosubstituted acetylenes using Rh catalysts provide the cis-transoidal polyacetylenes. ${ }^{37}$ The poly(2) formed with catalyst $\mathbf{1}$ had relatively high cis content comparable to the Rh-based polymer (runs $1,4)$, while those with Mo and W catalysts had much lower cis contents (runs 2,3). It is noteworthy that, although the polymerizations with $\mathrm{Ru}, \mathrm{W}$, and Mo catalysts should all proceed via the metathesis mechanism, the cis content of the Ru-based polymer 
Polymerization of Substituted Acetylenes by the Ru Carbene

Table III. Polymerization of 2 by various catalysts

\begin{tabular}{|c|c|c|c|c|c|}
\hline \multirow[b]{2}{*}{ Run } & \multirow[b]{2}{*}{ Catalyst } & \multicolumn{4}{|c|}{ Polymer $^{d}$} \\
\hline & & $\begin{array}{l}\text { Yield } \\
(\%)\end{array}$ & $M_{\mathrm{n}}^{\mathrm{e}}$ & $M_{\mathrm{w}} / M_{\mathrm{n}}^{\mathrm{e}}$ & $\begin{array}{c}\text { cis content } \\
(\%)^{\mathrm{f}}\end{array}$ \\
\hline \multirow{2}{*}{$1^{\mathrm{a}}$} & \multirow{2}{*}[(\mathrm{nbd})\mathrm{RhCl}]{$_{2}$} & \multirow{2}{*}{36} & $237,000(88 \%)^{\mathrm{g}}$ & 2.34 & \multirow{2}{*}{83} \\
\hline & & & $8800(12 \%)^{\mathrm{g}}$ & 1.20 & \\
\hline $2^{b}$ & $\mathrm{MoOCl}_{4} / n-\mathrm{Bu}_{4} \mathrm{Sn}$ & 45 & 9900 & 1.53 & ${ }^{\mathrm{h}}$ \\
\hline $3^{b}$ & $\mathrm{WOCl}_{4} / n-\mathrm{Bu}_{4} \mathrm{Sn}$ & 35 & 4500 & 1.30 & $-^{\mathrm{h}}$ \\
\hline $4^{c}$ & 1 & 24 & 25,500 & 2.63 & 75 \\
\hline
\end{tabular}

${ }^{\mathrm{a}}$ In $\mathrm{CH}_{3} \mathrm{CN}$ at $30^{\circ} \mathrm{C}$ for $24 \mathrm{~h}$; $[\mathrm{Rh}]=10 \mathrm{mM},[\mathrm{M}]_{0}=1.0 \mathrm{M} .{ }^{\mathrm{b}} \mathrm{In}$ toluene at $60^{\circ} \mathrm{C}$ for $24 \mathrm{~h}$; [Cat $]=$ $20 \mathrm{mM},\left[n-\mathrm{Bu}_{4} \mathrm{Sn}\right]=20 \mathrm{mM},[\mathrm{M}]_{0}=0.50 \mathrm{M} .{ }^{\mathrm{c}} \mathrm{At} 80^{\circ} \mathrm{C}$ for $24 \mathrm{~h}$; neat, $[\mathrm{M}]_{0} /[\mathrm{Ru}]=100 .{ }^{\mathrm{d}}$ Methanol-insoluble part. ${ }^{\mathrm{e}}$ Measured by GPC. ${ }^{\mathrm{f}}$ Determined by ${ }^{1} \mathrm{H} \mathrm{NMR}$ (in $\mathrm{CHCl}_{3}$, at $50{ }^{\circ} \mathrm{C}$ ). ${ }^{\mathrm{g}}$ Peak area ratio in GPC measurement. ${ }^{\mathrm{h}}$ The signals of the main-chain olefinic proton were too broad and small; the cis contents are assumed to be lower than $60 \%$.
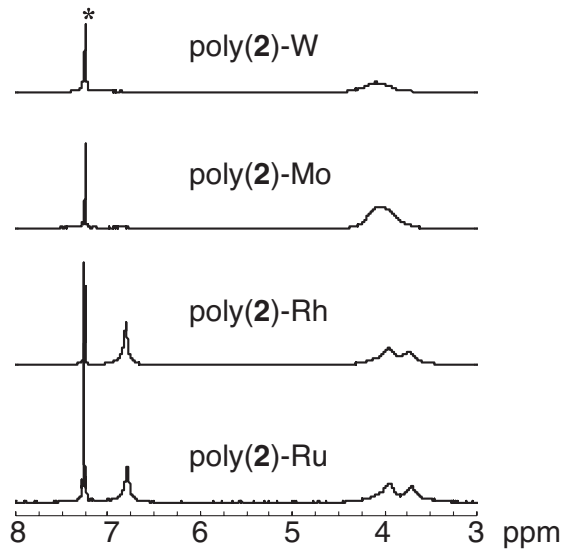

Figure 1. ${ }^{1} \mathrm{H}$ NMR spectra of poly(2)s obtained with various catalysts (samples from Table III; measured in $\mathrm{CDCl}_{3}$ at $50^{\circ} \mathrm{C}$ ).

was significantly higher than those of $\mathrm{W}$ - and Mobased counterparts. This difference may be accounted for by the presence of bulky ligands in Ru catalyst $\mathbf{1}$, which should control the geometric structure more strongly.

\section{Polymerization of Monomer 3}

Although the polymerization of monomer $3 \mathrm{did}$ not proceed in any of toluene, THF, 1,2-dichloroethene, acetonitrile, ethyl acetate, and DMSO as solvents, its bulk polymerization took place, and so it was examined under various conditions (Table IV). When $[\mathrm{M}]_{0} /[\mathrm{Ru}]=100$, polymer was hardly obtained at $60^{\circ} \mathrm{C}$, while polymer with $M_{\mathrm{n}}=96,900$ was formed in $16 \%$ yield at $80^{\circ} \mathrm{C}$ (run 2). With increasing temperature to $120^{\circ} \mathrm{C}$, the polymer yield did not change, but the molecular weight decreased to 12,300 (run 3). This is a similar tendency to the case of monomer $\mathbf{2}$, and the optimal polymerization temperature is concluded to be $80^{\circ} \mathrm{C}$. When the $[\mathrm{M}]_{0} /[\mathrm{Ru}]$ ratio was varied with keeping the polymerization temperature at $80{ }^{\circ} \mathrm{C}$, the polymer yield improved to $42 \%$ at $[\mathrm{M}]_{0} /[\mathrm{Ru}]=25$ (run 5). When the polymerization
Table IV. Bulk polymerization of $\mathbf{3}$ by catalyst $\mathbf{1}^{\mathrm{a}}$

\begin{tabular}{ccccccc}
\hline & & & \multicolumn{4}{c}{ Polymer $^{\mathrm{a}}$} \\
\cline { 4 - 7 } Run & $\begin{array}{c}\text { Temperature } \\
\left({ }^{\circ} \mathrm{C}\right)\end{array}$ & {$[\mathrm{M}]_{0} /[\mathrm{Ru}]$} & $\begin{array}{c}\text { Time } \\
(\mathrm{d})\end{array}$ & $\begin{array}{c}\text { Yield } \\
(\%)\end{array}$ & $M_{\mathrm{n}}{ }^{\mathrm{b}}$ & $M_{\mathrm{w}} / M_{\mathrm{n}}{ }^{\mathrm{b}}$ \\
\hline 1 & 60 & 100 & 1 & Trace & - & - \\
2 & 80 & 100 & 1 & 16 & 96,900 & 2.56 \\
3 & 120 & 100 & 1 & 16 & 12,300 & 2.15 \\
4 & 80 & 10 & 1 & 25 & 26,100 & 2.05 \\
5 & 80 & 25 & 1 & 42 & 60,700 & 2.22 \\
6 & 80 & 50 & 1 & 35 & 95,500 & 1.91 \\
7 & 80 & 200 & 1 & 10 & 107,400 & 2.39 \\
8 & 80 & 100 & 7 & 48 & 83,300 & 1.98 \\
9 & 80 & 200 & 7 & 39 & 92,400 & 2.01 \\
\hline
\end{tabular}

${ }^{\mathrm{a}}$ For $24 \mathrm{~h} .{ }^{\mathrm{b}}$ Methanol-insoluble part. ${ }^{\mathrm{c}}$ Measured by GPC.

time was extended to $7 \mathrm{~d}$ at $[\mathrm{M}]_{0} /[\mathrm{Ru}]=100$ and 200 , the polymer yield increased up to 48 and $39 \%$, respectively (runs 8,9 ).

The time course of the polymerization of monomer $\mathbf{3}$ by $\mathbf{1}$ is shown in Figure 2. Both monomer conversion and polymer yield leveled off after $24 \mathrm{~h}$. The $M_{\mathrm{n}}$ reached 99,000 in $1 \mathrm{~h}$ and then somewhat decreased, while the polydispersity slightly increased.

\section{Structure and Properties of Poly(3)}

Poly(3) samples were synthesized by using various catalysts to study the polymer structure; the results of the polymerizations are shown in Table V. ${ }^{35,38}$ Whereas the Ta-, Mo-, and W-based polymers had colors of yellow to orange-yellow, only the Ru-based samples was virtually white in the powdery state. For the sake of comparison, poly(DPA) (DPA: diphenylacetylene) samples were also prepared, as is listed in Table V.

Figure 3 shows the IR spectra of monomer 3 and the four poly $(3)$ samples. A peak at $1530 \mathrm{~cm}^{-1}$ which is absent in the spectrum of monomer $\mathbf{3}$ appears in those of $\operatorname{poly}(\mathbf{3}) \mathrm{s}$. This peak is assignable to the stretching vibration of alternating $\mathrm{C}=\mathrm{C}$ bonds in the 
Table V. Polymerization of $\mathbf{3}$ and DPA by various catalysts

\begin{tabular}{ccccccc}
\hline & & & \multicolumn{3}{c}{ Polymer $^{\mathrm{d}}$} \\
\cline { 3 - 6 } Run & Monomer & Catalyst & $\begin{array}{c}\text { Yield } \\
(\%)\end{array}$ & $M_{\mathrm{n}}{ }^{\mathrm{e}}$ & $M_{\mathrm{w}} / M_{\mathrm{n}}{ }^{\mathrm{e}}$ & Color \\
\hline $1^{\mathrm{a}}$ & $\mathbf{3}$ & $\mathrm{TaCl}_{5} / n-\mathrm{Bu}_{4} \mathrm{Sn}$ & 80 & 70,200 & 3.14 & Orange-yellow \\
$2^{\mathrm{a}}$ & $\mathbf{3}$ & $\mathrm{MoCl}_{5} / \mathrm{Ph}_{4} \mathrm{Sn}$ & 21 & 48,900 & 10.5 & Dark yellow \\
$3^{\mathrm{a}}$ & $\mathbf{3}$ & $\mathrm{WCl}_{6} / \mathrm{Ph}_{4} \mathrm{Sn}$ & 29 & 11,200 & 2.31 & Bright yellow \\
$4^{\mathrm{b}}$ & $\mathbf{3}$ & $\mathbf{1}$ & 42 & 60,700 & 2.22 & White \\
$5^{\mathrm{a}}$ & $\mathrm{DPA}$ & $\mathrm{TaCl}_{5} / n-\mathrm{Bu}_{4} \mathrm{Sn}$ & 47 & insoluble & - & Yellow \\
$6^{\mathrm{c}}$ & $\mathrm{DPA}$ & $\mathbf{1}$ & 22 & insoluble & - & White \\
\hline
\end{tabular}

${ }^{\mathrm{a}}$ In toluene at $80^{\circ} \mathrm{C}$ for $24 \mathrm{~h}$; [Cat $]=20 \mathrm{mM},[\mathrm{Sn}]=40 \mathrm{mM},[\mathrm{M}]_{0}=0.20 \mathrm{M} .{ }^{\mathrm{b}}$ At $80^{\circ} \mathrm{C}$ for $24 \mathrm{~h}$; neat, $[\mathrm{M}]_{0} /[\mathrm{Ru}]=25 .{ }^{\mathrm{c}}$ At $80{ }^{\circ} \mathrm{C}$ for $24 \mathrm{~h}$; neat, $[\mathrm{M}]_{0} /[\mathrm{Ru}]=100 .{ }^{\mathrm{d}}$ Methanol-insoluble part. ${ }^{\mathrm{e}}$ Measured by GPC. ${ }^{\mathrm{f}}$ Insoluble in any organic solvents including $\mathrm{CHCl}_{3}$, toluene, and THF.
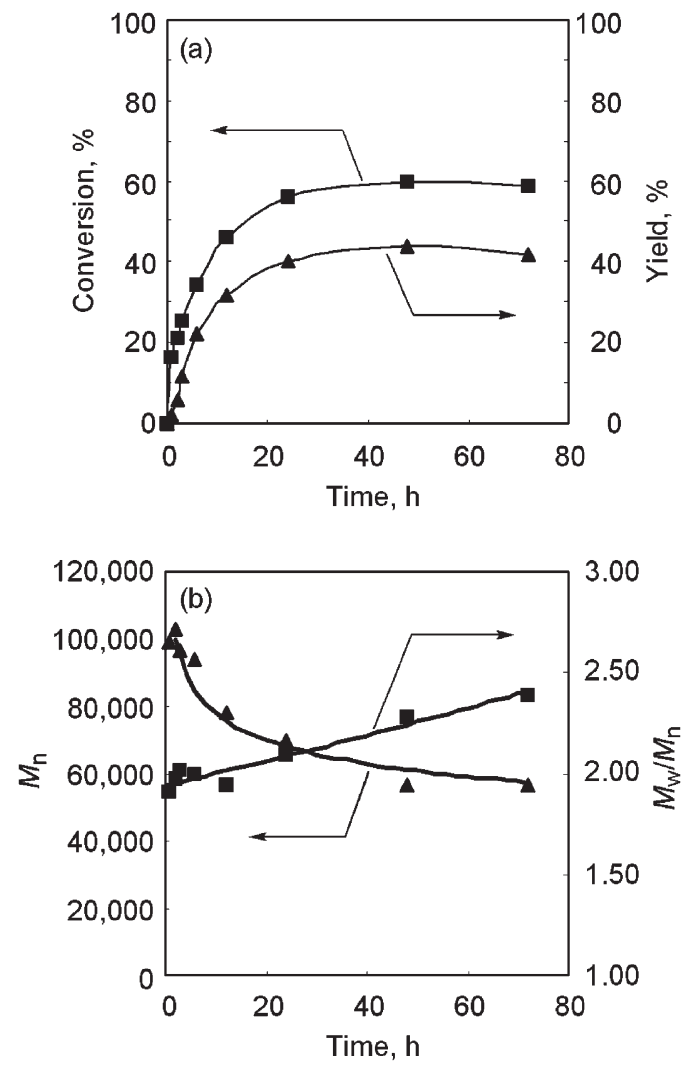

Figure 2. Time profile of the bulk polymerization of monomer 3 by 1 . (polymerized in toluene at $80^{\circ} \mathrm{C} ;[\mathrm{M}]_{0} /[\mathrm{Ru}]=25$; the polymer yield denotes the yield of methanol-insoluble part.)

main-chain which are generated by polymerization of the acetylene moiety. Slight differences are seen in the ranges of $500-700,900-1100$ and $1300-1750 \mathrm{~cm}^{-1}$ in the four spectra of poly $(\mathbf{3}) \mathrm{s}$, which appears to reflect differences in the structure of the polymers.

As seen in Figure 4, the ${ }^{13} \mathrm{C}$ NMR spectra of Ta-, $\mathrm{W}-$, and Mo-based poly (3)s in $\mathrm{CDCl}_{3}$ solution display seven peaks in the $\mathrm{C}_{s p^{2}}$ region; i.e. sharp peaks at 126 , 127 and $128 \mathrm{ppm}$, a large peak with a shoulder at $131 \mathrm{ppm}$, a small peak at $136 \mathrm{ppm}$ and two sharp peaks at 144 and $146 \mathrm{ppm}$. These spectra are very similar to one another. On the other hand, the spec-

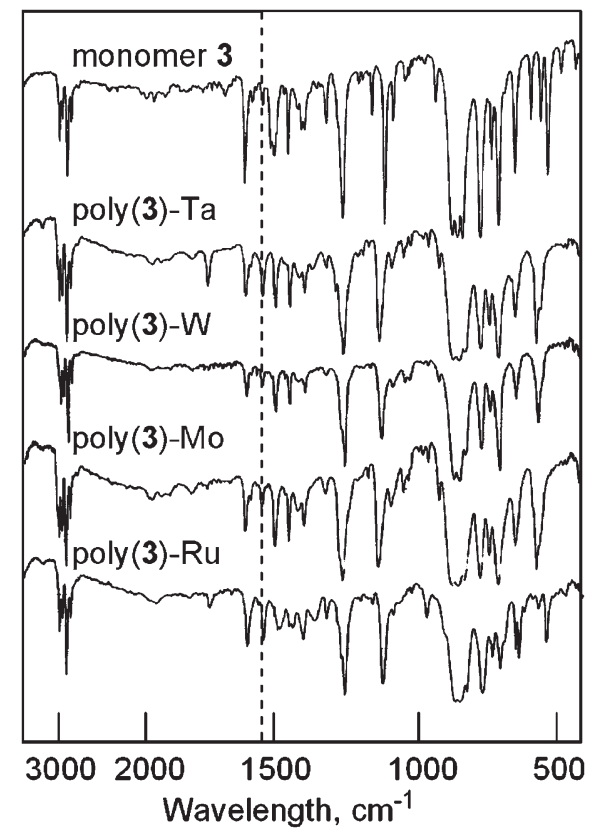

Figure 3. IR spectra $(\mathrm{KBr}$ pellet) of poly $(3)$ s obtained with various catalysts (samples from Table V). Dot line is $1530 \mathrm{~cm}^{-1}$.

trum of the Ru-based poly $(3)$ is quite different from those of the other three polymers. This indicates that the Ru-based polymer has a different structure from those of the other polymers, but the detailed difference is not clear from these spectra.

Whereas the UV/vis spectra of poly $(3)$ s obtained with the conventional catalysts display two peaks around 375 and $435 \mathrm{~nm}$, that of the polymer with catalyst 1 possessed only one peak at $290 \mathrm{~nm}$ (Figure 5a). This indicates that the conjugation length of the latter polymer is much shorter than those of the former polymers. The fluorescence spectra of poly $(3)$ s exited at their absorption maxima were shown in Figure 5 b. The fluorescence spectra of the former three polymers are similar to one another, while that with catalyst $\mathbf{1}$ is quite different.

The TGA curves of these poly $(3)$ s measured in air are more or less different from one another. According 


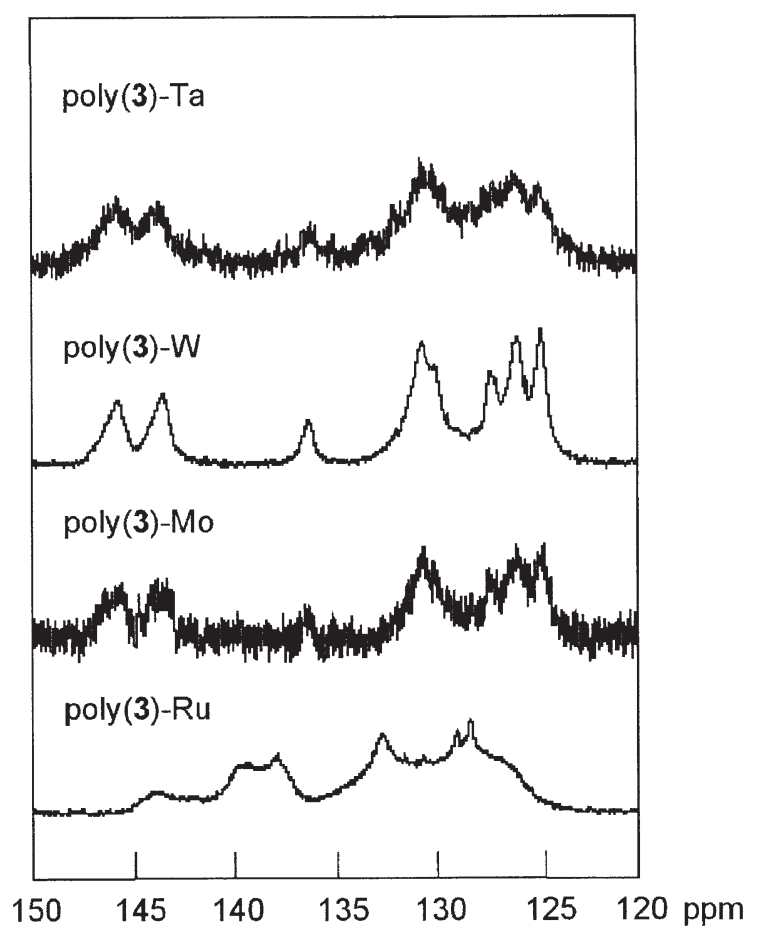

Figure 4. ${ }^{13} \mathrm{C}$ NMR spectra of poly $(3)$ s obtained with various catalysts (samples from Table $\mathrm{V}$; measured in $\mathrm{CDCl}_{3}$ at room temperature).

the onset temperature $\left(T_{0}\right)$ of weight loss, the polymers with Ta and Mo $\left(\sim 450^{\circ} \mathrm{C}\right)$ are more stable than those with $\mathrm{Ru}$ and $\mathrm{W}\left(\sim 350^{\circ} \mathrm{C}\right)$ (Figure 6). Furthermore, the $\mathrm{Ru}$-based polymer loses weight steeply with increasing temperature. While the rather low $T_{0}$ of the Ru-based polymer should be due to the difference in polymer structure from other polymers, that of the W-based polymer may stem from its low molecular weight. The residue at around $700^{\circ} \mathrm{C}$ is attributed to $\mathrm{SiO}_{2}$ whose weight is theoretically $24 \%$ of the polymer.

All of the $\operatorname{poly}(\mathbf{3})$ samples were totally soluble in toluene, THF, and chloroform (Table VI). Among these samples, some differences were observed; the Ta-based polymer was insoluble in hexane, the Mo-based one was partly soluble, and the $\mathrm{W}$ - and Ru-based ones were completely soluble.

\section{Solid-State ${ }^{13}$ C NMR}

The solid-state ${ }^{13} \mathrm{C}$ NMR spectra of a series of poly $(3)$ s were measured in order to gain more detailed information about polymer structure. The spectra of poly(DPA)s synthesized with both $\mathrm{TaCl}_{5} / n-\mathrm{Bu}_{4} \mathrm{Sn}$ and $\mathrm{Ru}$ catalyst $\mathbf{1}$ were also studied for comparison because poly(DPA) is not accompanied by the problem of head-to-tail and head-to-head. Figure 7 exhibits the $110-160 \mathrm{ppm}$ region of the ${ }^{13} \mathrm{C} \mathrm{CP} / \mathrm{MAS}$ spectra of poly(3)s and poly(DPA)s. The spectra of poly(3) and poly(DPA) obtained with the Ta catalyst resemble each other. The same thing can be said with $\operatorname{poly}(\mathbf{3})$
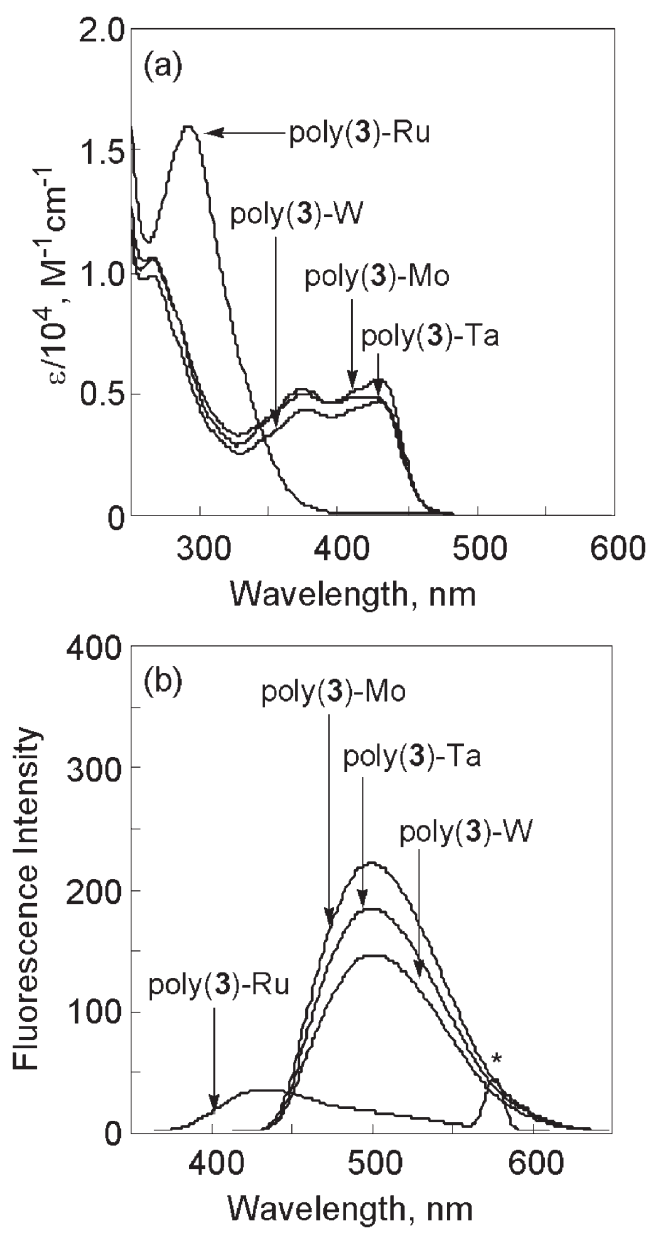

Figure 5. (a) Uv-vis spectra of poly(3)s obtained with various catalysts (samples from Table V; measured in $\mathrm{CHCl}_{3}, \mathrm{c}=1.0 \times$ $\left.10^{-4} \mathrm{M}\right)$. (b) Fluorescence spectra of poly $(3)$ s obtained with various catalysts (samples from Table $\mathrm{V}$; measured in $\mathrm{CHCl}_{3}$; excited at $292 \mathrm{~nm}(\mathrm{Ru}), 374.5 \mathrm{~nm}(\mathrm{Mo})$, or $376 \mathrm{~nm}(\mathrm{Ta}, \mathrm{W}) ; \mathrm{c}=1.0 \times$ $\left.10^{-5} \mathrm{M}\right)$. Asterisked is an optical ghost peak.

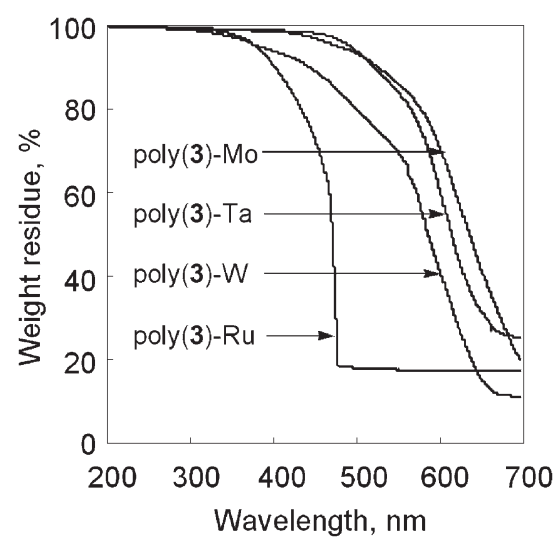

Figure 6. TGA curves of poly $(3)$ s obtained with various catalysts (samples from Table V; measured in air; heating rate $10^{\circ} \mathrm{C} /$ $\min )$.

and poly(DPA) formed with $\mathrm{Ru}$ catalyst 1 . Since poly(DPA) does not involve the problem of regioregularity, the difference in the spectra of the poly- 
Table VI. Solubility of $\operatorname{poly}(\mathbf{3})$ obtained with various catalysts

\begin{tabular}{|c|c|c|c|c|}
\hline \multirow[b]{2}{*}{ Solvent } & \multicolumn{4}{|c|}{ Poly(3) } \\
\hline & $\mathrm{TaCl}_{5} / n-\mathrm{Bu}_{4} \mathrm{Sn}$ & $\mathrm{MoCl}_{5} / \mathrm{Ph}_{4} \mathrm{Sn}$ & $\mathrm{WCl}_{6} / \mathrm{Ph}_{4} \mathrm{Sn}$ & Ru cat. (1) \\
\hline DMSO & - & - & - & - \\
\hline DMF & - & \pm & \pm & \pm \\
\hline Acetone & - & \pm & \pm & \pm \\
\hline $\mathrm{CH}_{2} \mathrm{Cl}_{2}$ & + & + & + & + \\
\hline THF & + & + & + & + \\
\hline$o$-Dichlorobenzene & + & + & + & + \\
\hline Chlorobenzene & + & + & + & + \\
\hline $\mathrm{CHCl}_{3}$ & + & + & + & + \\
\hline Anisole & + & \pm & + & + \\
\hline $\mathrm{Et}_{2} \mathrm{O}$ & + & + & + & + \\
\hline Benzene & + & + & + & + \\
\hline Toluene & + & + & + & + \\
\hline $\mathrm{CCl}_{4}$ & + & + & + & + \\
\hline Cyclohexane & + & + & + & + \\
\hline Hexane & - & \pm & + & + \\
\hline
\end{tabular}

+ : soluble; \pm : partly soluble; -: insoluble.
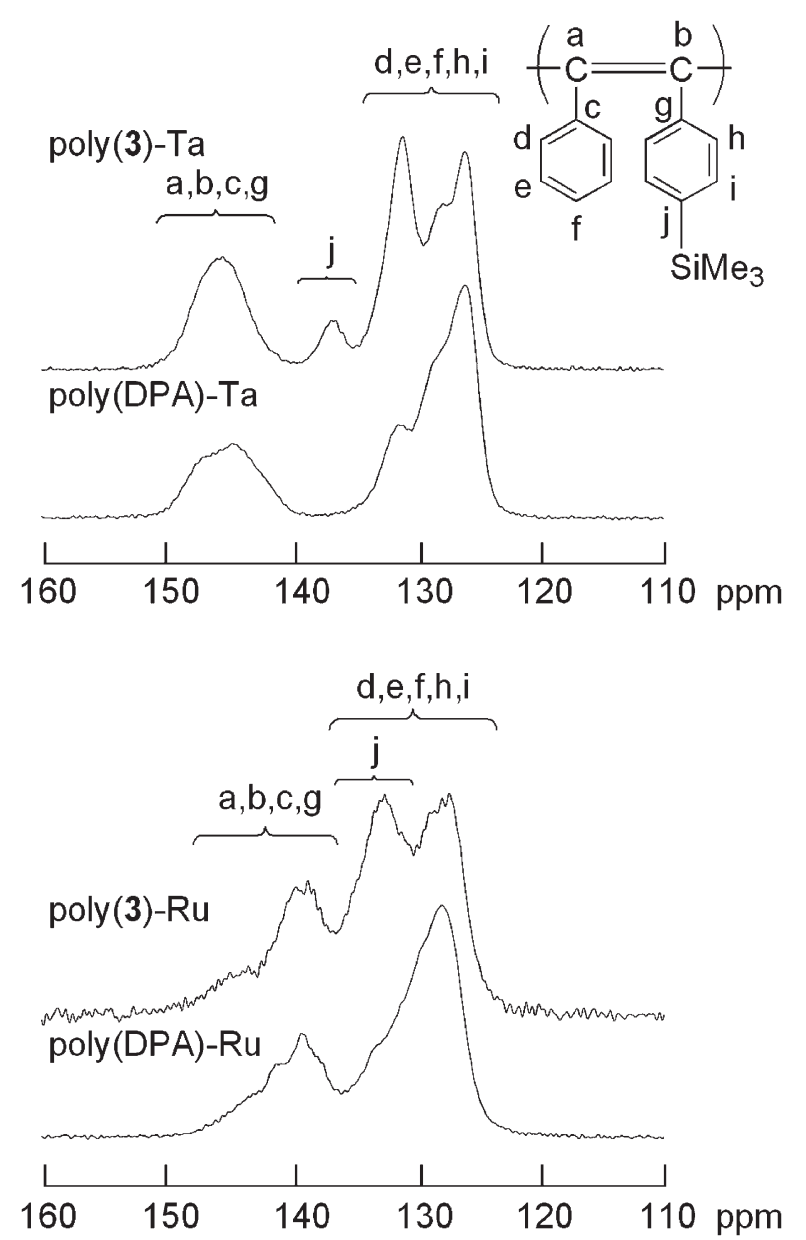

Figure 7. ${ }^{13} \mathrm{C} \mathrm{CP} / \mathrm{MAS}$ spectra of poly $(3) \mathrm{s}$ and poly(DPA)s.

mers with catalysts is attributable to the difference in the main-chain configuration.

The ${ }^{13} \mathrm{C} \mathrm{CP}+\mathrm{DDPh}$ (dipolar dephasing)/MAS experiments were performed to assign each peak in
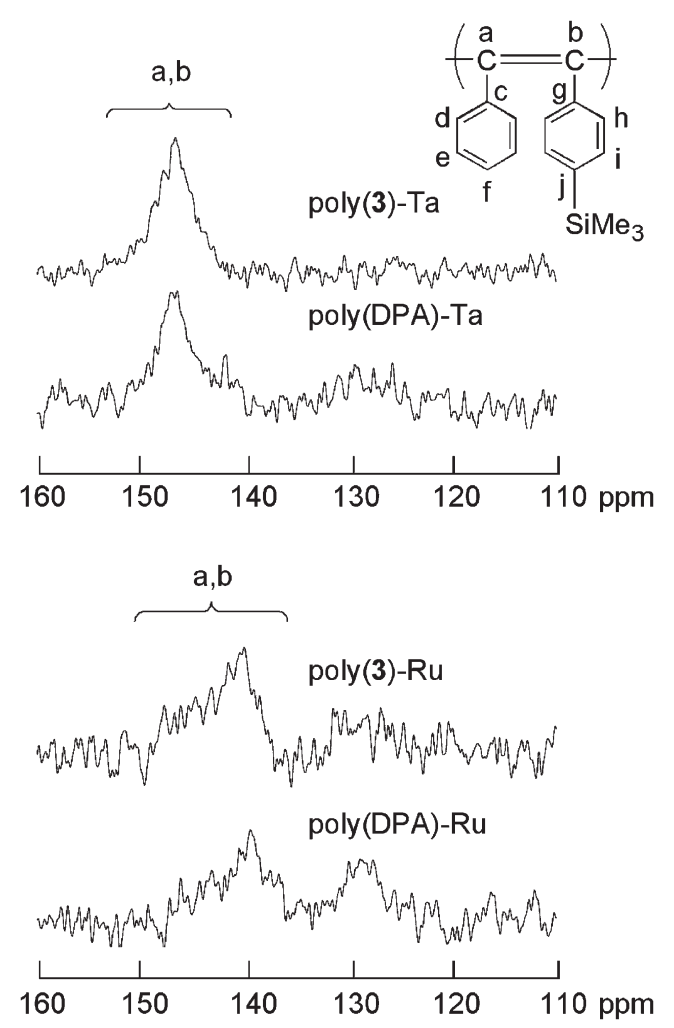

Figure 8. ${ }^{13} \mathrm{C} \mathrm{CP}+\mathrm{DDPh} / \mathrm{MAS}$ spectra of poly $(\mathbf{3}) \mathrm{s}$ and poly(DPA)s (the dephasing time $100 \mu \mathrm{s}$ ).

Figure 7. Dipolar dephasing spectra were observed by inserting a dephasing period between the $\mathrm{CP}$ period and detection. When the dephasing time was $100 \mu \mathrm{s}$, the Ta-based poly $(\mathbf{3})$ displayed relatively strong peaks around $146 \mathrm{ppm}$, while the Ru-based $\operatorname{poly}(3)$ displayed a relatively broad peak around $140 \mathrm{ppm}$ with a shoulder positioning at $145 \mathrm{ppm}$ (Figure 8). These peaks are generally assigned to the carbons that do 

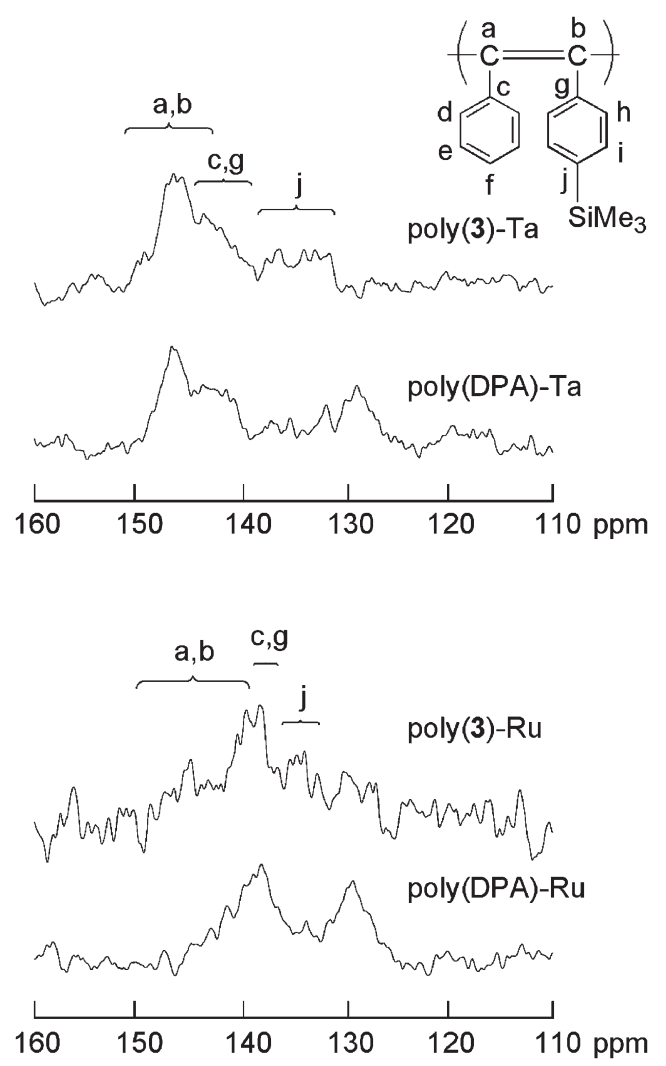

Figure 9. ${ }^{13} \mathrm{C} \mathrm{CP}+\mathrm{DDPh} / \mathrm{MAS}$ spectra of poly(3)s and poly(DPA)s (the dephasing time $60 \mu \mathrm{s}$ ).

not have strong interaction with hydrogen atoms, and thus should be derived from main-chain carbon atoms of each polymer. By adopting a dephasing time of $60 \mu \mathrm{s}$, new peaks appeared at a higher magnetic field (Figure 9). Namely, two peaks were newly observed at $142 \mathrm{ppm}$ as a shoulder and at $136 \mathrm{ppm}$ in Ta-based poly(3), and at 138 and $134 \mathrm{ppm}$ in Ru-based poly(3). These peaks can be assigned to the substituted carbons of the phenyl rings. Further, when compared with the spectra of poly(DPA), the peaks at 142 and $136 \mathrm{ppm}$ in the Ta-based poly $(3)$ are assigned to the benzene carbons attached to the main chain and the silyl group, respectively; on the other hand, the peaks at 138 and $134 \mathrm{ppm}$ in the Ru-based poly $(3)$ are based on the benzene carbons attached to the main chain and the silyl group, respectively. From the above discussion, the signals of ${ }^{13} \mathrm{C}$ NMR spectra are assigned as shown in Figure 7. It is noteworthy that not only the mainchain carbons but also benzene carbons exhibit different chemical shifts depending on the kind of catalysts used. Further, it is noted that the Ru-based polymers have a broader distribution in the main-chain configuration according to the signals of the 146-140 ppm region. At this moment, we can say from the solidstate ${ }^{13} \mathrm{C}$ NMR spectra that the $\mathrm{Ru}$ - and Ta-based poly $(3)$ s have clearly different geometric structures in the main chain to each other.
Acknowledgment. The authors thank Materia Inc., USA, for the generous donation of Grubbs-Hoveyda catalyst (1). Helpful discussions with Professor Hoveyda and Professor Buchmeiser are highly appreciated. This work was supported by a Grant-in-Aid for Scientific Research from Japan Society for the Promotion of Science.

\section{REFERENCES}

1. For reviews of substituted polyacetylenes, see:

a) T. Masuda and F. Sanda, In "Handbook of Metathesis," Vol. 3, R. H. Grubbs, Ed. Wiley-VCH, Weinheim, 2003, Chapt. 3, p 11.

b) R. Nomura and T. Masuda, In "Encyclopedia of Polymer Science and Technology," Vol. 1A, J. I. Kroshwitz, Ed., Wiley, 2003, p 1.

c) J. W. Y. Lam and B. Z. Tang, J. Polym. Sci., Part A: Polym. Chem., 41, 2607 (2003).

d) K. Nagai, T. Masuda, T. Nakagawa, B. D. Freeman, and I. Pinnau, Prog. Polym. Sci., 26, 721 (2001).

e) S. K. Choi, Y. S. Gal, S. H. Jin, and H. K. Kim, Chem. Rev., 100, 1645 (2000).

2. R. R. Schrock, S. Luo, J. C. Lee, Jr., N. C. Zanetti, and W. M. Davis, J. Am. Chem. Soc., 118, 3883 (1996).

3. R. R. Schrock, S. Luo, N. C. Zanetti, and H. H. Fox, Organometallics, 13, 3396 (1994).

4. R. Schlund, R. R. Schrock, and W. E. Crowe, J. Am. Chem. Soc., 111, 8004 (1989).

5. K. C. Wallace, A. H. Liu, W. M. Davis, and R. R. Schrock, Organometallics, 8, 644 (1989).

6. J. Sedlacek and J. Vohlidal, Collect. Czech. Chem. Commun., 68, 1745 (2003).

7. M. Tabata, T. Sone, and Y. Sadahiro, Macromol. Chem. Phys., 200, 265 (1999).

8. Y. Kishimoto, P. Eckerle, M. Miyatake, T. Ikariya, and R. Noyori, J. Am. Chem. Soc., 116, 12131 (1994).

9. Y. Kishimoto, M. Itou, T. Miyatake, T. Ikariya, and R. Noyori, Macromolecules, 28, 6662 (1995).

10. Y. Misumi and T. Masuda, Macromolecules, 31, 7572 (1998).

11. M. Miyake, Y. Misumi, and T. Masuda, Macromolecules, 33, 6636 (2000).

12. J. Deng, J. Tabei, M. Shiotsuki, F. Sanda, and T. Masuda, Macromolecules, 37, 9715 (2004).

13. J. Deng, J. Tabei, M. Shiotsuki, F. Sanda, and T. Masuda, Polymer, 45, 7395 (2004).

14. J. Deng, J. Tabei, M. Shiotsuki, F. Sanda, and T. Masuda, Macromolecules, 37, 7156 (2004).

15. J. Deng, J. Tabei, M. Shiotsuki, F. Sanda, and T. Masuda, Macromolecules, 37, 5149 (2004).

16. J. Deng, J. Tabei, M. Shiotsuki, F. Sanda, and T. Masuda, Macromolecules, 37, 1891 (2004).

17. J. Tabei, R. Nomura, F. Sanda, and T. Masuda, Macromolecules, 37, 1175 (2004).

18. J. Tabei, R. Nomura, F. Sanda, and T. Masuda, Macromolecules, 36, 537 (2003).

19. M. Tabata, Y. Inada, K. Yokota, and Y. Nozaki, J. Macromol. Sci., Pure Appl. Chem., A31, 465 (1994). 
20. H. Nakako, R. Nomura, and T. Masuda, Macromolecules, 34, 1496 (2001).

21. R. Nomura, Y. Fukushima, H. Nakako, and T. Masuda, J. Am. Chem. Soc., 122, 8830 (2000).

22. H. Nakako, Y. Mayahara, R. Nomura, M. Tabata, and T. Masuda, Macromolecules, 33, 3978 (2000).

23. H. Nakako, R. Nomura, M. Tabata, and T. Masuda, Macromolecules, 32, 2861 (1999).

24. K. Maeda, H. Goto, and E. Yashima, Macromolecules, 34, 1160 (2001).

25. Y. Ashida, T. Sato, K. Morino, K. Maeda, Y. Okamoto, and E. Yashima, Macromolecules, 36, 3345 (2003).

26. B. Z. Tang, W. H. Poon, S. M. Leung, W. H. Leung, and H. Peng, Macromolecules, 30, 2209 (1997).

27. For reviews of Ru-catalyzed olefin metathesis, see: a) R. H. Grubbs, Ed., "Handbook of Metathesis," WileyVCH, Weinheim, 2003.

b) T. M. Trnka and R. H. Grubbs, Acc. Chem. Res., 34, 18 (2001).

c) R. H. Grubbs, Tetrahedron, 60, 7117 (2004).

28. T. M. Trnka, M. W. Day, and R. H. Grubbs, Organometallics, 20, 3845 (2001).
29. E. E. Schuehler, J. E. Williams, and M. B. Sponsler, Macromolecules, 37, 6255 (2004).

30. J. O. Kraus, M. T. Zarka, U. Ander, R. Weberskirch, O. Nuyken, and M. R. Buchmeiser, Angew. Chem. Int. Ed., 42, 5965 (2003).

31. J. O. Kraus, O. Nuyken, and M. R. Buchmeiser, Chem.Eur. J., 10, 2029 (2004).

32. A. H. Hoveyda, D. G. Gillingham, J. J. Van Veldhuizen, O. Kataoka, S. B. Garber, J. S. Kingsbury, and J. P. A. Harrity, Org. Biomol. Chem., 2, 8 (2004).

33. S. B. Garber, J. S. Kingsbury, B. L. Gray, and A. H. Hoveyda, J. Am. Chem. Soc., 122, 8168 (2000).

34. J. Cossy, S. Bouzbouz, and A. H. Hoveyda, J. Org. Chem., 624, 327 (2001).

35. K. Tsuchihara, T. Masuda, and T. Higashimura, Macromolecules, 21, 5816 (1992).

36. R. R. Schrock, J. Am. Chem. Soc., 93, 2397 (1971).

37. Y. Kishimoto, P. Eckerle, T. Miyatake, M. Kainosho, A. Ono, T. Ikariya, and R. Noyori, J. Am. Chem. Soc., 121, 12035 (1999).

38. The procedures for polymerization were the same as for the $\mathrm{TaCl}_{5} / n-\mathrm{Bu}_{4} \mathrm{Sn}$ one. 